\title{
HANFORD WASTE BLENDING AND THE VALUE OF RESEARCH: STOCHASTIC OPTIMIZATION AS A POLICY TOOL
}

\author{
Timothy Lawrence Johnson and Urmila M. Diwekar \\ Department of Engineering and Public Policy \\ Carnegie Mellon University
}

\begin{abstract}
A new optimization framework is applied to management of radioactive wastes stored in belowground tanks at the US Government's Hanford, WA, nuclear fuels facility. Current remediation plans call for vitrification of the tank contents. Blending of the wastes prior to glass formation reduces the amount of material required for processing, therefore decreasing disposal costs. Uncertainty in the tank contents, the error inherent in the glass property models governing vitrification, and computational difficulties, however, render determination of an optimal tankblend assignment a challenge to existing optimization techniques. Previous studies have focused exclusively on minimization of processing and disposal costs, ignoring such management-related dimensions as the value of reducing select sources of uncertainty. Moreover, the stochastic framework employed by these studies could not guarantee that the glass property requirements were met on more than a probabilistic basis. This paper presents a more flexible, efficient, and robust optimization framework that facilitates analysis of the trade-off in reducing select sources of uncertainty. Specifically, the prediction error of the glass property models is found to be more significant than variation in tank component mass fraction estimates, and constraint violations are traced to the need to meet a limited set of glass property characteristics.
\end{abstract}

\section{INTRODUCTION: OPTIMIZATION AS A POLICY TOOL}

This paper describes the application of a new optimization framework to a complex policy problem: remediation of high-level radioactive waste stored underground at the US government's Hanford nuclear fuels site. The use of optimization methods in policy analysis and research, while considerable in its potential, has not been fully appreciated in practice. The multiplicity of conflicting objectives and the need to act with incomplete information that characterize situations such as Hanford's combine with the computational and analytical demands of optimization techniques to discourage their use. Yet these tools can play a valuable role even where optimization is of secondary importance. Questions common to waste management, for instance, can be profitably framed in an optimization context. How conservative decision makers should be with respect to risks and where limited resources should be allocated in order to reduce uncertainty are but two examples.

The optimization framework described here extends the structure of previous assessments to examine such questions as they pertain to the Hanford waste remediation effort - dimensions of the problem that have been examined only on an ad hoc basis. The analysis utilizes a more flexible, efficient, and robust optimization model that facilitates analysis of the trade-off in reducing select sources of uncertainty. Key findings include identification of error in the glass property models governing waste vitrification as a more significant source of uncertainty than 


\section{WM'00 Conference, February 27 - March 2, 2000, Tucson, AZ}

imperfect knowledge of the tank contents. The analysis also isolates those glass property characteristics - framed as constraints in the optimization model - to which robustness of the vitrification process is most sensitive.

The paper first reviews the larger context of the Hanford waste remediation effort, emphasizing the need to find an optimal blend of the stored wastes prior to their immobilization in glass. A brief description of the optimization framework follows. Results are then presented, and the paper concludes with a discussion of the analysis.

\section{HANFORD WASTE MANAGEMENT}

The forty year rush to stay ahead of the Soviet Union in the nuclear arms race, coupled with the demands of military secrecy during the Cold War, rendered environmental concerns secondary to the requirements of national security $(1,2)$. The US Department of Energy's Hanford, WA site is one of many government facilities now confronting the emerging effects of this legacy. Buried beneath Hanford are 177 storage tanks, with capacities ranging from 50 thousand to one-million gallons, holding waste from nearly two-thirds of the weapons grade nuclear fuel produced in the US following World War II (3). Mixed into this chemical waste is high-level radioactive material, including strontium, cesium, and plutonium isotopes - the latter with a half-life of tenthousand years.

The short-term focus of the original fuel production did not consider the eventual disposal of its concomitant waste materials. The storage tanks, for instance, were originally built with an expected useful life of no more than a few decades, and poor documentation was kept as chemicals were added to the tanks, removed for waste management, evaporated to increase storage capacity, and juggled from one reservoir to the next (3). The long-term consequences of this situation would not be quite as serious if the waste could be maintained underground indefinitely. Known and suspected leaks, production of volatile hydrogen gas in the tanks, and uncertainty about the future of the Hanford site, however, preclude this option $(4,5)$.

The current - but evolving - remediation strategy consists of a multistage process, beginning with characterization and preprocessing of the tank contents, separation of low- and high-level radioactive components, and conversion of both waste streams into glass "logs" for permanent disposal in a national repository $(3,6)$. The blending problem, on which this paper focuses, applies to the glass formation process - referred to as "vitrification" - and seeks combinations of tank wastes that minimize the amount of glass produced.

\section{OPTIMIZING VITRIFICATION}

Selective blending of the tank wastes prior to vitrification reduces the amount of glass produced only because the tank contents differ $(7,8)$. A non-homogeneous mixture of gases, liquids, slurries, and solids, the tank contents include: salts, organic complexants and their aging products, different metals, low- and high-level nuclear waste, and water (3). In order to convert these substances into glass, various oxides (e.g., $\mathrm{SiO}_{2}, \mathrm{~B}_{2} \mathrm{O}_{3}, \mathrm{Na}_{2} \mathrm{O}, \mathrm{Li}_{2} \mathrm{O}, \mathrm{CaO}$, and $\mathrm{MgO}$ ) collectively referred to as "frit" - must be added to the waste as it melts. 


\section{WM'00 Conference, February 27 - March 2, 2000, Tucson, AZ}

Blending takes advantage of the fact that the frit constituents are present to varying degrees in each tank; a selective combination of wastes therefore reduces the need to add frit during vitrification by matching tanks with complementary frit requirements (8). In addition, blending decreases the proportion of so-called "limiting" components in the combined waste streams. The presence of these components adversely affects the vitrification process; sodium, for instance, reduces glass durability, while aluminum increases both the melt temperature of the material and its viscosity (7). Hence, selective blending of the tank contents increases the probability that vitrification will succeed, reduces frit requirements (i.e., achieves a greater waste-to-frit mass ratio), and minimizes the volume of glass produced.

Blending involves a two-stage decision process: assignment of individual tanks to a given blend and determination of frit requirements. The latter decision depends on the contents of each tank, and is governed by both analytical and empirical glass property models derived for the Hanford tank wastes $(9,10)$. The resulting constraints pertain to the vitrification process - rather than characteristics of the subsequent glass - and include: bounds on the waste component mass fractions; crystallinity requirements; solubility limits; and attributes of the molten glass, including its viscosity, electrical conductivity, and liquidus temperature $(8,11,12)$.

This nested structure is typical of problems in combinatorial optimization, where a number of discrete decisions (e.g., the tank-blend assignments) must be made prior to the optimization of some function of continuous characteristics (e.g., the frit mass of each blend) - a dependency that prevents these decisions from being decoupled $(13,14)$. Solution techniques must cycle between the discrete and continuous decision levels, until a satisfactory "optimum" is reached. This computational complexity prevents the use of a heuristic, "back of the envelope," approach; a formal optimization strategy is therefore required.

The determination of an optimal set of tank blends is not a trivial task, and - like other problems in stochastic optimization - challenges current techniques. Optimization methods seek to minimize (or maximize) the value of an objective function, subject to both equality and inequality constraints on its constituent decision variables (see, e.g., 15). The most general optimization procedures restrict analysis to a deterministic set of linear objective and constraint equations. Research has focused on extending these methods to more realistic applications involving nonlinear functions of the decision variables, multiple layers of discrete and continuous variables, and probabilistic equations.

Models like the blending problem, however, remain difficult to solve in a computationally tractable framework without resorting to the excessive use of simplifying assumptions. Such obstacles have rendered traditional mathematical programming techniques ineffective as a means of finding an optimal combination of the Hanford tanks. These include:

- Difficulty incorporating probabilistic events and parametric uncertainties in a way that recognizes their full importance. In the blending problem, significant uncertainties exist in both the contents of each tank and in the prediction error of the empirical glass property models. 


\section{WM'00 Conference, February 27 - March 2, 2000, Tucson, AZ}

- The tendency to become "trapped" at local minima. Evaluation of several initial points is therefore required to ensure that a "global" solution is found - increasing the computational burden.

- A combinatorial "explosion" of possible solutions. A subset of 21 of the 177 Hanford tanks, for instance, partitioned into three blends of seven tanks each produces 66.5 million tankblend combinations.

- A failure to recognize reduction of uncertainty as an important objective in itself. Previous efforts to address the blending problem (e.g., 8,11) have focused solely on the cost of vitrification (i.e., minimization of frit, which is equivalent to minimizing glass volume, and hence, disposal costs). Significant policy dimensions related to the vitrification process have thus been ignored.

A realistic assessment of the Hanford blending problem therefore requires the use of improved optimization techniques, especially as they relate to decision making under uncertainty. The framework employed here utilizes a stochastic annealing-nonlinear programming (STA-NLP) algorithm; this sequential association of optimization techniques reflects the two-stage decision structure typical of problems like Hanford's tank waste management (14). The iterative optimization process consists of three "loops":

- a sampling loop that calculates expected values of the waste component mass fractions from empirical distributions of the tank contents;

- a continuous decision loop (NLP) that uses the mass fraction expected values to determine the amount of frit required by a given blend of tanks, subject to a series of glass-property constraints;

- and a discrete decision loop (STA) that selects tank-blend configurations that minimize the objective function - the sum of the expected frit mass, its associated sample variance, and other terms of interest.

The STA-NLP algorithm cycles through these loops, accepting tank-blend assignments with lower values of the objective function until a stopping criteria is met. The introduction of random tank-blend assignments reduces the likelihood of the algorithm coming to rest at a "local," sub-optimal value of its objective. Compared to previous analyses, the new optimization framework is more efficient, reducing processor time on a high-end workstation from days to a matter of hours. For a complete description of the framework's application to the Hanford blending problem, see Johnson and Diwekar (16).

\section{VARIANCE AS AN ATTRIBUTE: THE ANALYSIS OF UNCERTAINTY}

Sources of uncertainty in the blending problem have important technical implications and reflect significant aspects of the policy-making process surrounding Hanford's waste management efforts. Expansion of the analytical objective from minimization of frit to include different sources of variation therefore represents a novel methodological development. This section illustrates the new optimization framework's advantages through progressive extensions to the blending problem's objective; the following section discusses the results. All data is taken from Narayan, et al. (8) and Hopkins, et al. (17). 


\section{Base Objective: Minimization of Frit}

A subset of twelve tanks divided evenly into three blends forms the basis of this analysis. Initial remediation efforts at the Hanford site will focus on a limited number of storage tanks; the criticality of a tank's condition (its position on a "watch list") and the compatibility of its contents with the demands of vitrification will govern the selection process (3).

The blending scheme planned for the Hanford tank waste sits on a continuum of strategies between vitrification without blending and a "total blend" of all tank materials into one waste stream (8). The total blend alternative, in theory, requires the least amount of frit; the impossibility of combining all tank wastes into one batch, however, precludes its use in practice. The no-blend and total solutions are of interest nevertheless as they provide bounds against which changes in discrete-blend frit requirements may be compared. A deterministic analysis of the blending problem (which replaces the empirical probability distributions of all uncertain variables with their modes) yields a further basis for comparison.

Table 1 presents the frit requirements from these preliminary solution schemes, using the basecase objective:

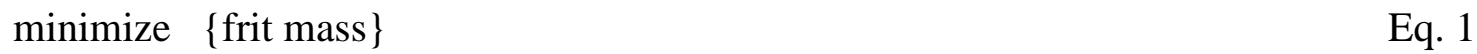

TABLE 1 -- Frit requirements as determined by basic solution techniques.

\begin{tabular}{|l|c|}
\hline Solution Method & Required Frit Mass (kg) \\
\hline Worst case (no blending) & 13410 \\
\hline Best case (one blend of all tanks) & 9839 \\
\hline Deterministic solution (STA-NLP without sampling) & 11161 \\
\hline Single attribute stochastic solution (STA-NLP with sampling) & 10060 \\
\hline
\end{tabular}

\section{Robustness: Minimizing Variance}

The variance in frit requirements, $\operatorname{var}_{\text {frit }}$, is a measure of the robustness of the optimum solution and constraint satisfaction. The magnitude of $\operatorname{var}_{\text {frit }}$, for instance, directly affects the probability that the glass property constraints are met when actual (i.e., sample) values of the waste component mass fractions are used in place of their sample means. Hence, there is a desire to keep this source of variation as low as possible. Including variance as an attribute produces the following objective (frit mass here is an expected value, and all terms have been scaled to the same order of magnitude):

minimize frit mass $+\mathrm{w}_{1} * \operatorname{var}_{\text {frit }}$

Eq. 2

The number of constraint violations produced by using waste component mass fraction sample values (rather than their means - for which the constraints are always met) provides an indication of a particular tank-blend configuration's feasibility. Table 2 presents results of a parametric 
analysis of changes in the priority given to variance minimization relative to frit mass reduction (i.e., in $\mathrm{w}_{1}$ ). The following sub-section builds on this analysis.

TABLE 2 -- The balance between expected value and variance minimization.

\begin{tabular}{|c|c|c|c|}
\hline $\begin{array}{c}\text { Relative Weight of } \\
\text { var }_{\text {rrit }}\end{array}$ & $\begin{array}{c}\text { Frit Mass } \\
(\mathrm{kg})\end{array}$ & $\begin{array}{c}\sqrt{\left(\text { var }_{\text {frit }}\right)} \\
(\mathrm{kg})\end{array}$ & $\begin{array}{c}\text { \% Constraints } \\
\text { Violated }\end{array}$ \\
\hline 0.50 & 10255 & 293 & 11 \\
\hline 1.0 & 10075 & 190 & 6 \\
\hline 2.0 & 10647 & 138 & 2 \\
\hline 4.0 & 11558 & 118 & 0 \\
\hline
\end{tabular}

\section{Reducing Uncertainty}

The ability to incorporate additional variance-related terms into the objective function illustrates stochastic optimization's potential as a policy tool. Better characterization of the Hanford tank wastes and glass property models, for instance, would result in lower frit requirements. The decrease in frit mass that a reduction in uncertainty yields, however, must be weighed against the opportunity costs of pursuing other objectives. The extensions introduced here facilitate this analysis: an examination of the trade-offs inherent in allocating scarce resources among researchoriented activities. Such extensions are generalizable to similar situations, which are ubiquitous, especially in nuclear waste management where the long-lived nature of the waste creates large uncertainties.

The analysis rests on a key assumption: that time spent on research increases understanding, and therefore decreases variation in quantitative estimates derived from this knowledge. Research activities, however, introduce their own costs and risks; hence, time spent learning and experimenting needs to be optimized. While reducing uncertainty is profitable, the time required to achieve a reduction tempers the benefit. The augmented objective captures this trade-off:

minimize \{costs of waste disposal and opportunity costs of reducing uncertainty\}

Processing and disposal costs are once again represented by the expected frit mass and its associated variance. As illustrated below, the sampling variance of the tank waste component mass fractions and the uncertainty in the empirical glass property models (through its effect on constraint widths) serve as proxies for the opportunity costs of tank waste characterization and study of the glass formation process.

The expanded blending objective therefore attempts to minimize frit mass, but - beyond finding an optimal tank-blend assignment - balances the extent to which improved waste characterization and more accurate glass property models contribute to this goal. Research efforts, for instance, could aim at easing the constraint bounds via improvements in the glass property models' prediction error; as the constraints govern frit requirements, less conservative 


\section{WM'00 Conference, February 27 - March 2, 2000, Tucson, AZ}

limits in an optimization framework translate into the need for a smaller safety margin and therefore less frit. Proportional relaxation of the constraints, however, carries an increasing penalty: the opportunity costs of related research activities (e.g., tank characterization).

To understand how the augmented blending objective captures this trade-off in mathematical terms, note that the type of investigation relevant to the problem will exhibit long-run diminishing marginal returns, as uncertainty declines with time spent on research. For characterization of the tank waste components, an exponential relationship between sampling variance and time provides an adequate first-order approximation of this dependence:

uncertainty in waste composition $\Leftrightarrow \operatorname{var}_{\text {samp }} \propto \exp (-$ time)

or

time $\propto-\ln \left(\operatorname{var}_{\mathrm{samp}}\right)$

A similar relationship holds for the constraint width term. Note, however, that the width of the constraint bounds varies inversely with the prediction error of the empirical glass property models:

time $\propto-\ln ($ prediction error $) \propto-\ln (\text { constraint width })^{-1}=\ln ($ constraint width $)$

Once again, the model captures the need to prioritize research objectives by seeking tank-blend combinations with larger input sampling variances and prediction errors (i.e., narrower constraint bounds). Excessive values, however, are simultaneously penalized through their detrimental effect on the expected frit mass and its associated sample variance. The optimum reflects a balance in this trade-off: a low frit mass and var ${ }_{\text {frit }}$, with moderate values of var ${ }_{\text {samp }}$ and the constraint widths. Combining these arguments, the augmented blending objective (with all terms scaled accordingly) becomes:

minimize frit mass $+\mathrm{w}_{1} * \mathrm{var}_{\text {frit }}-\mathrm{w}_{2} * \ln \Sigma \mathrm{var}_{\text {samp }}+\mathrm{w}_{3} * \ln \Sigma$ constraint width

Eq. 6

Weights on the terms of equation 6 provide a means of assessing priorities with respect to the conflicting goals of decreasing the costs of vitrification and minimizing the opportunity costs of reducing uncertainty. Table 3 presents a qualitative summary of results from such an assessment (see Johnson and Diwekar [16] for quantitative details). Note that tank-blend assignments vary depending on the weight of each term in the objective function. 
WM'00 Conference, February 27 - March 2, 2000, Tucson, AZ

TABLE 3 - A qualitative summary of the trade-off in reducing sources of variation.

\begin{tabular}{|c|c|c|c|}
\hline Focus of Research & $\mathrm{E}[$ frit mass $]$ & $\begin{array}{l}\text { Result } \\
\text { var }_{\text {frit }}\end{array}$ & $\%$ constraint violations \\
\hline $\begin{array}{l}\text { Robustness/ minimization of frit } \\
\text { variance (increase } \mathrm{w}_{1} \text { ) }\end{array}$ & Increases & Decreases & Decreases \\
\hline $\begin{array}{l}\text { Minimize time devoted to tank } \\
\text { characterization (increase } \mathrm{w}_{2} \text { ) }\end{array}$ & Increases & Increases & Increases \\
\hline $\begin{array}{l}\text { Minimize time devoted to improving } \\
\text { glass property models (increase } \mathrm{w}_{3} \text { ) }\end{array}$ & Does not change & Decreases & Increases \\
\hline
\end{tabular}

\section{DISCUSSION: THE IMPLICATIONS OF UNCERTAINTY}

The results from the previous section have significant implications for the blending problem. The importance of attending to matters of robustness, for instance, is apparent in Table 2: as reduction in frit variance is emphasized, the proportion of constraint violations decreases to zero and the frit masses become clustered more tightly around their mean. The expected frit mass, however, is uniformly higher when reduction of its sample variance is a priority - a compromise that illustrates the balance between reducing the volume of immobilized waste and increasing the probability that vitrification succeeds. The augmented optimization algorithm facilitates such an analysis.

Beyond providing a framework in which similar trade-offs may be assessed, however, policy makers desire answers to specific questions. Note that the most important question concerning the blending problem is not minimization of frit mass, per se; indeed, consideration of the entire context of Hanford's remediation effort and the politics of radioactive waste disposal may decrease the priority of reducing frit mass - especially on the order of the savings seen above (compare Tables 1 and 2). More important are questions concerning uncertainty: To what extent is imperfect information acceptable, and where should scarce resources be allocated to leverage the impact of this narrow part of Hanford's waste remediation effort on the whole of its strategy? Not all sources of uncertainty, after all, are significant. In pursuing answers to such questions, stochastic optimization functions more as an exploratory tool than as a means of providing "one best" solution.

The preceding analysis illustrates this capacity. An examination of the constraints, for instance, reveals that the crystallinity requirements are most consistently violated, with the $\mathrm{P}_{2} \mathrm{O}_{5}$ solubility limit and the component bound on $\mathrm{Al}_{2} \mathrm{O}_{3}$ are frequently exceeded as well . Ideally, more effort should be placed on reducing the error in the corresponding glass property models and on additional waste pretreatment efforts designed to mitigate the effects of these limiting components. 
Perhaps more significant is the ability to determine which sources of uncertainty need to be reduced and which, in contrast, may be tolerated. The relationship, however, between the sample variance and constraint width terms, the frit requirements, and the violation of constraints is complicated. As described, the $\operatorname{var}_{\text {samp }}$ and constraint width terms enter the objective function as penalties; considered in isolation of their effects on frit mass, larger values of these terms are desired. The "benefit" of greater uncertainty in the tank waste distributions and glass property models, however, is balanced by its detrimental effect on the expected frit mass and its variance.

Results from the preceding section illustrate this relationship. As the weight on the sampling variance term increases (i.e., as less weight is placed on characterizing the tank wastes), variation in frit mass increases and constraint violations become more numerous. This effect is not surprising: a change in the variance of the waste component sampling distributions leads to a proportionate shift in the frit variance - and a similar impact on both the average frit mass and extent of constraint violations.

Compared to changes in the weight given to var $_{\text {samp }}$, however, the variance in frit mass decreases while the percentage of constraint violations increases with more liberal constraint widths (compare parts (a) and (b) of Figures 1 and 2); greater uncertainty in the glass property models translates into narrower constraint bounds, and a smaller range across which frit requirements may vary without consequence. This impact on process robustness leads to the conclusion that improvements in the glass property models should take priority over efforts to reduce uncertainty in the tank waste composition. The presence of nonlinearities in the glass property models/constraints - which inflate the effects of variance - provides one explanation for the pattern of these results. 


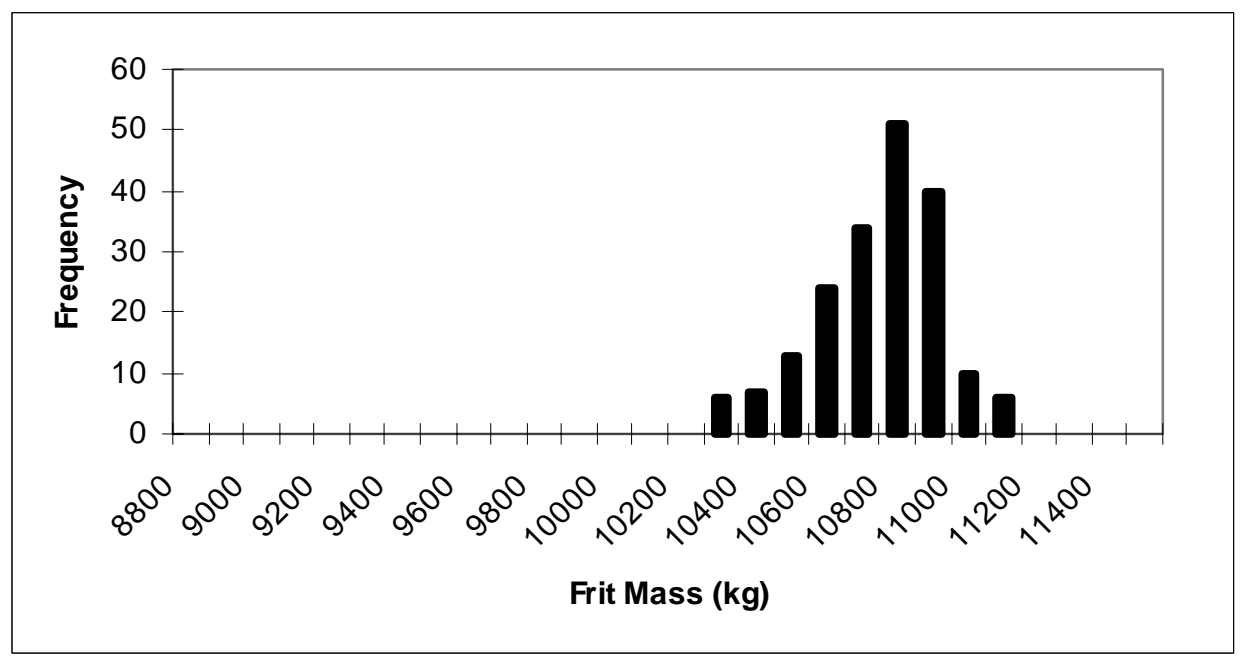

(a)

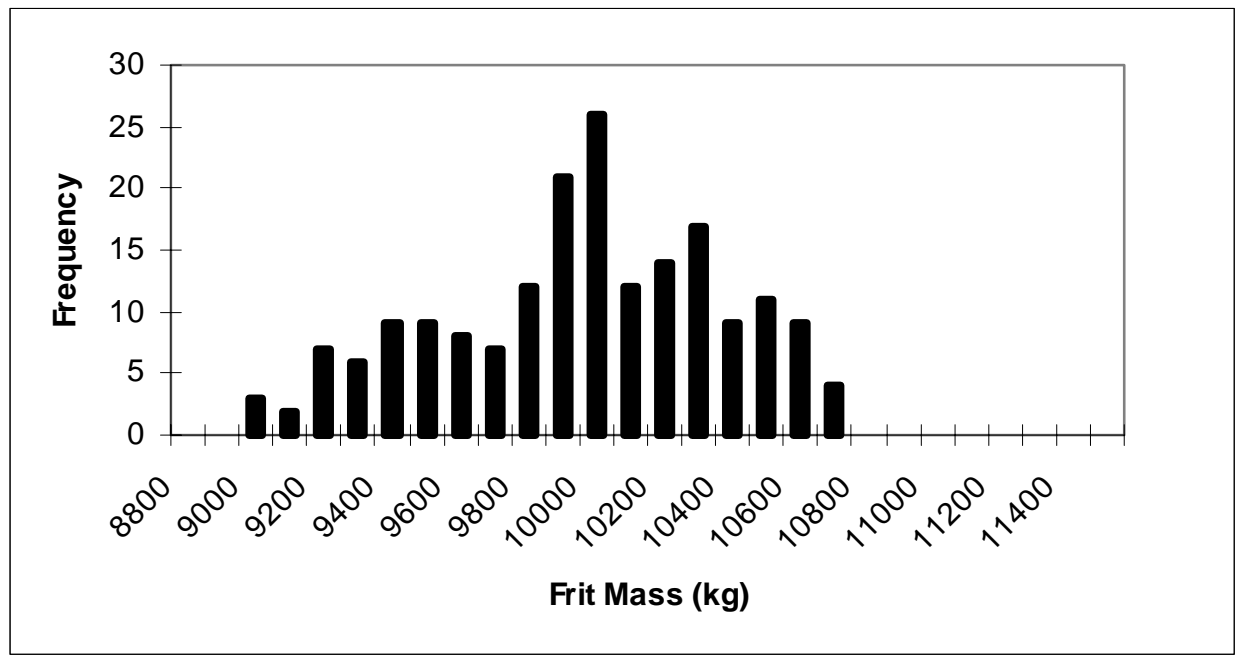

(b)

FIGURE 1 -- Distribution of frit masses for different weights on the constraint width objective term; (a) $\mathrm{w}_{3}=1.0$, (b) $\mathrm{w}_{3}=3.0$. 
WM'00 Conference, February 27 - March 2, 2000, Tucson, AZ

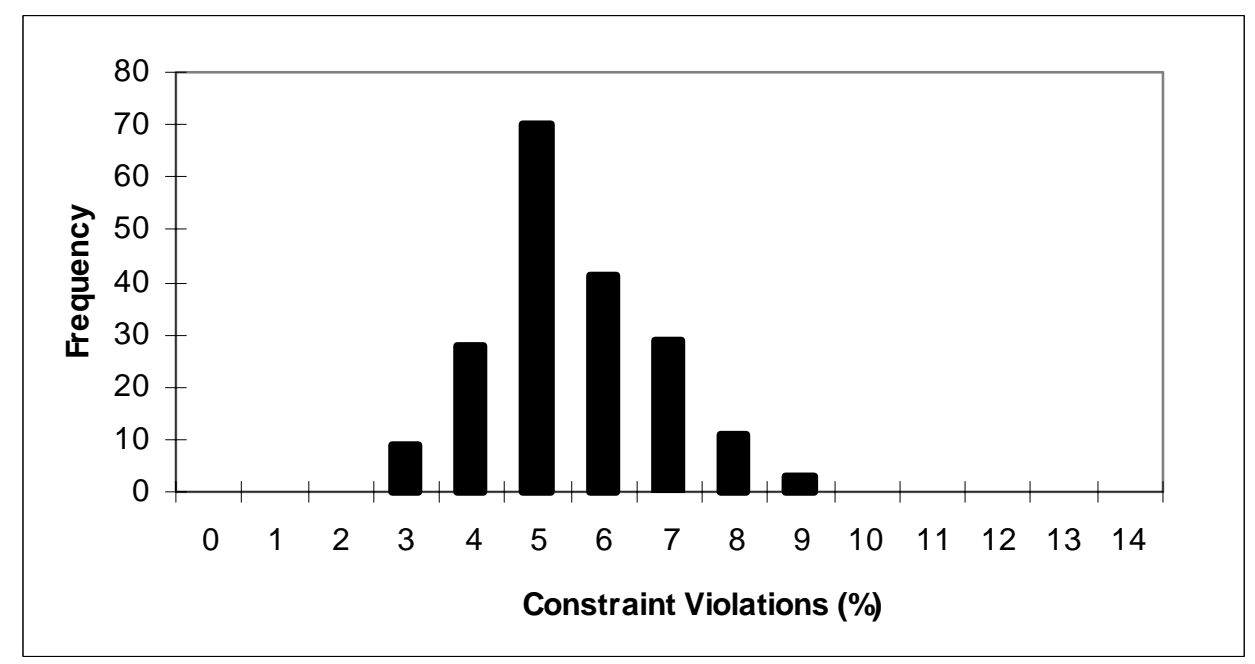

(a)

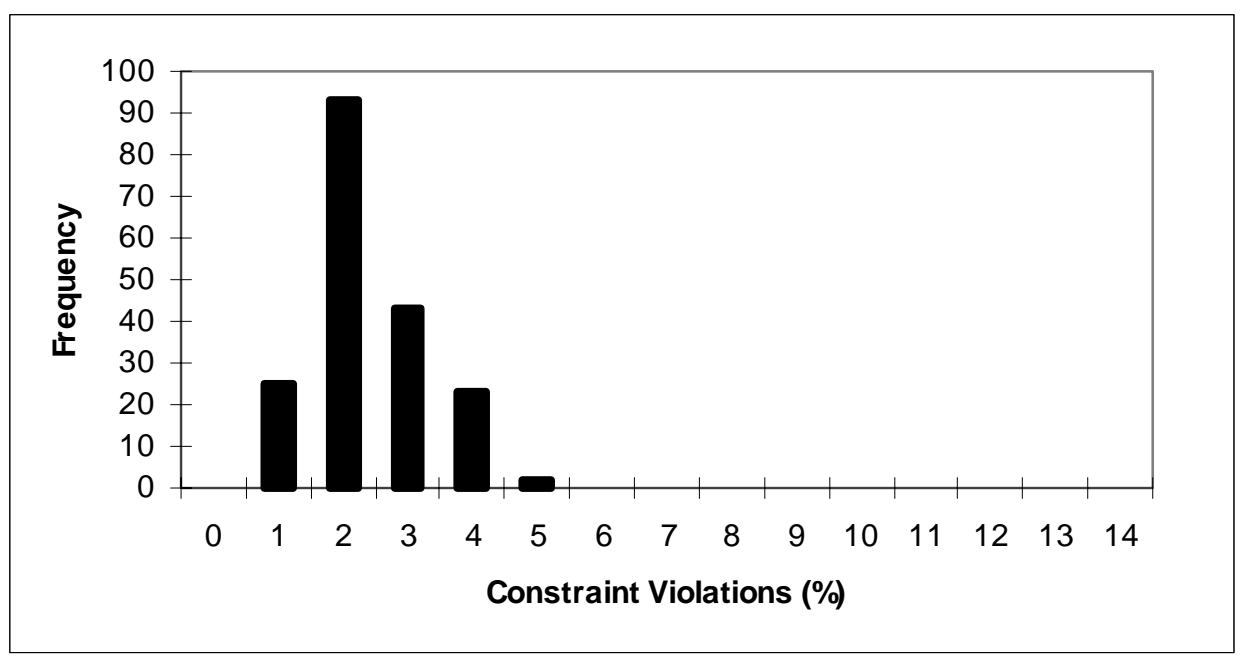

(b)

FIGURE 2 - Distribution of constraint violations for different weights on the constraint width objective term; (a) $\mathrm{w}_{3}=1.0$, (b) $\mathrm{w}_{3}=3.0$.

\section{CONCLUSIONS}

Augmented optimization techniques such as that used in this analysis can facilitate a realistic examination of questions pertaining to uncertainty, and incorporate the multiattribute nature of the trade-offs that arise when knowledge is incomplete. Applied to Hanford's tank waste management problem, the predictive error of the glass property models was found to be the most 
significant source of uncertainty - a prioritizationthat pervious approaches to the blending problem could not address. Not all sources of uncertainty are consequential; the ability to distinguish between those sources that are important and those that may be tolerated is therefore valuable in a decision-making environment.

In addition, the value of flexibility in an analytical tool was illustrated by the inclusion of multiple variance-related terms as objective function attributes - terms representing the conflicting sources of uncertainty surrounding waste remediation at Hanford. Extension of the blending objective facilitated a structured evaluation of an important management issue: the trade-off between living with uncertainty now versus the value of increasing knowledge. The costs of vitrification in terms of material requirements must be balanced with the need to ensure robustness of the glass formation process. The analysis presented here demonstrated how this issue may be addressed in an exploratory manner using optimization techniques - in a situation where optimization, per se, is of secondary concern.

Stochastic optimization deserves to be included in the policy analysis toolbox. The computational and algorithmic difficulty of adapting situations like the Hanford tank blending problem to an appropriate framework, however, have limited its application. Further experience and development will increase the value of optimization techniques as a means of gaining insight into complex problems - includingthose that the growing need to manage hazardous wastes will continue to present.

\section{ACKNOWLEDGMENTS}

We wish to thank Dr. Jared Cohon of Carnegie Mellon University for his ideas and guidance. This work was sponsored in part by the National Science Foundation, under grant CTS-9613561.

\section{REFERENCES}

1. US Congress, Office of Technology Assessment (1991). Complex Cleanup: The Environmental Legacy of Nuclear Weapons Production, OTA-O-484. Washington, DC: US Government Printing Office.

2. Gerber, M.S. (1992). On the Home Front: The Cold War Legacy of the Hanford Nuclear Site, Omaha, NE: University of Nebraska Press.

3. Gephart, R.E. and Lundgren, R.E. (1995). "Hanford tank clean up: A guide to understanding the technical issues." Report BNWL-645, Richland, WA: Pacific Northwest Laboratory.

4. Probst, Katherine N., Pilling, Carolyn A. and Dunn, Karen T. (1996). "Cleaning up the nuclear weapons complex: Exploring new approaches.” Discussion Paper 96-25, Washington, DC: Resources for the Future.

5. US General Accounting Office (1994). "Nuclear cleanup: Completion of standards and effectiveness of land use planning are uncertain." Report GAO/RCED-94-114, Washington, DC: US General Accounting Office. 
6. Nuclear News (1997). "DOE selects Hanford tank waste cleanup plan.” Nuclear News 40, 49.

7. Hrma, P.R. and Bailey, A.W. (1995). "High level waste at Hanford: Potential for waste loading maximization.” Report PNL-SA-26441, Richland, WA: Pacific Northwest Laboratory.

8. Narayan, Venkatesh, Urmila M. Diwekar and Mark Hoza (1996). "Synthesizing optimal waste blends." Industrial and Engineering Chemistry Research 35, 3519-3527.

9. Mendel, J.E., Rawest, W.A., Turcotte, R.P. and McElroy, J.L. (1980). "Physical properties of glass for immobilization of high-level radioactive waste." Nuclear and Chemical Waste Management 1, 17-28.

10. Hrma, P.R. and Piepel, G.F. (1992). "Property/composition relationships for Hanford waste vitrification plant glasses -- Preliminary results through CVS-II Phase 2." Report PHTD-9203.01/K897, Richland, WA: Pacific Northwest Laboratory.

11. Hoza, M. (1994). "Multipurpose optimization models for high-level waste vitrification." Proceedings of the International Topical Meeting on Nuclear and Hazardous Waste Management -- SPECTRUM 94, La Grange Park, IL: American Nuclear Society, 1072-1077.

12. Jantzen, C.M. and Brown, K.G. (1993). "Statistical process control of glass manufactured for nuclear waste disposal.” American Ceramic Society Bulletin 72, 55-9.

13. Painton, Laura and Diwekar, Urmila (1995). "Stochastic annealing for synthesis under uncertainty." European Journal of Operational Research 83, 489-502.

14. Chaudhuri, Prosenjit D. and Diwekar, Urmila M. (1998). "Pollution prevention design." In Robert A. Meyers (Ed.) Encyclopedia of Environmental Analysis and Remediation, NY: John Wiley and Sons.

15. Ravindran, A., Phillips, Don T. and Solberg, James J. (1987). Operations Research: Principles and Practice (Second Edition), NY: John Wiley and Sons.

16. Johnson, Timothy L. and Urmila M. Diwekar (in press). "Hanford waste blending and the value of research: Stochastic optimization as a policy tool." Submitted to the Journal of Multi-Criteria Decision Analysis (March, 1999).

17. Hopkins, D.F., Hoza, M. and Lo Presti, C.A. (1994). "FY94 optimal waste loading models development." Report PVTD-C94-02.04D, Richland, WA: Pacific Northwest Laboratory. 